\title{
Comment to: sudden death caused by acute pulmonary embolism after laparoscopic total extraperitoneal inguinal hernia repair: a case report and literature review. C. Yang, L. Zhu
}

\author{
S. Yasri ${ }^{1} \cdot$ V. Wiwanitkit ${ }^{2}$
}

Received: 9 February 2017/Accepted: 4 April 2017/Published online: 13 April 2017

(C) Springer-Verlag France 2017

\section{Dear Editor,}

We read the recent case report by Yang and $\mathrm{Zu}$ with a great interest [1]. In this report, the case of acute pulmonary embolism after inguinal hernia repair is reported [1]. Yang and Zhu noted that "clinicians should consider both the strength of individual risk factors and the cumulative weight of all risk factors prior to surgery [1]." The call for concern on risk assessment is also raised. In fact, pulmonary embolism is an unexpected problem that can be seen in any surgery. The problem can be seen in either obese or non-obese patients and is very hard to predict [2]. The standard classical pre-operative assessment usually lacks the ability to predict the problem. How to successfully predict the problem is the big issue. In a recent report, Pannucci et al. reported the new assessment tool that might be applicable [3]. Nevertheless, the verification in different settings is required. The important point should be the concern and awareness of the practitioners about the problem and early recognition and prompt management should be the important point to correspond to the problem.

This comment refers to the article available at doi:10.1007/s10029017-1587-x.

S. Yasri

sorayasri@outlook.co.th

1 KMT Primary Care Center, Bangkok, Thailand

2 Hainan Medical University, Haikou, China
Compliance with ethical standards

Conflict of interest All authors declare that they have no conflict of interest.

Ethical approval For this type of study formal consent is not required.

Human and animal rights This article does not contain any studies with human participants or animals performed by any of the authors.

Informed consent None.

\section{References}

1. Yang C, Zhu L (2017) Sudden death caused by acute pulmonary embolism after laparoscopic total extraperitoneal inguinal hernia repair: a case report and literature review. Hernia. doi:10.1007/ s10029-017-1587-x

2. Wang L, Pryor AD, Altieri MS, Romeiser JL, Talamini MA, Shroyer L, Telem DA (2015) Perioperative rates of deep vein thrombosis and pulmonary embolism in normal weight vs obese and morbidly obese surgical patients in the era post venous thromboembolism prophylaxis guidelines. Am J Surg 210(5):859-863. doi:10.1016/j.amjsurg.2015.01.021

3. Pannucci CJ, Basta MN, Fischer JP, Kovach SJ (2015) Creation and validation of a condition-specific venous thromboembolism risk assessment tool for ventral hernia repair. Surgery 158(5):1304-1313. doi:10.1016/j.surg.2015.04.001 